\title{
PROSPECT OF STEM CELL THERAPY TO AVOID CYTOKINE STORM IN SEVERE COVID-19
}

\author{
J. A. PAWITAN $1,2,3^{*}$
}

1Department of Histology, Faculty of Medicine, Universitas Indonesia, Jakarta, Indonesia, ${ }^{2}$ Stem Cell Medical Technology Integrated Service Unit, Dr. Cipto Mangunkusumo General Hospital/Faculty of Medicine Universitas Indonesia, Indonesia, ${ }^{3}$ Stem Cell and Tissue Engineering Research Center, Indonesia Medical Education and Research Institute (IMERI), Faculty of Medicine Universitas Indonesia, Indonesia Email: jeanneadiwip@gmail.com

Received: 28 Jun 2020, Revised and Accepted: 07 Aug 2020

\section{ABSTRACT}

Severe COVID-19 cases are mostly due to severe inflammatory reaction and cytokine storm, which may lead to multiple organ failure and death. Until recently, there is no proven effective treatment for severe COVID-19. Mesenchymal stem cells (MSCs) have anti-inflammatory and regenerative properties. Therefore, they are supposed to work on COVID-19, which has failed to recover using other treatments. Therefore, studies are needed to determine the best tissue source of MSCs, the dose, repeat, and route of administration. For this review, we searched various databases, i.e. Pubmed, Science Direct, Springer, and WHO website using keywords: "mesenchymal stem cells" and "COVID-19" at 7 May 2020, without time limits. Various clinical trials on the use of MSCs for COVID-19 were registered, and initial results were reported. Initial results were promising but should be interpreted cautiously, as one was a case report, another one was case series, and one was a preliminary study of seven treated patients compared to three controls, where the baseline conditions were unequal. Therefore, well design randomized clinical trials are needed to get more robust prove.

Keywords: SARS-CoV-2, COVID-19, Mesenchymal stem cells, Immune-modulation, Anti-inflammation, Cytokine storm

(C) 2020 The Authors. Published by Innovare Academic Sciences Pvt Ltd. This is an open access article under the CC BY license (http://creativecommons.org/licenses/by/4.0/) DOI: http://dx.doi.org/10.22159/ijap.2020v12i5.38886. Journal homepage: https://innovareacademics.in/journals/index.php/ijap Speedy peer review was done as the subject of the manuscript was related with pandemic.

\section{INTRODUCTION}

The first pneumonia case, which was presumably due to a novel Coronavirus, was identified in Wuhan, China on 14 November [1] but cases were communicated to WHO on 31 December 2020 as pneumonia of unknown cause [2]. On 27 December, three patients, who were ill for four to seven days, were admitted to a hospital in Wuhan, and on 30 December their broncho-alveolar-lavage samples were collected. RNA extraction, direct PCR, whole-genome sequencing, and virus isolation from the lavage samples showed the presence of a new betacoronavirus with more than $85 \%$ similarity to a bat SARS-like CoV (bat-SL-CoVZC45, MG772933.1) [3]. The new virus, which was previously named 2019 novel coronavirus (2019$\mathrm{nCoV}$ ), is named SARS-CoV-2 and the disease it causes is named coronavirus disease (COVID-19) [4]. The new virus infects cells through angiotensin-converting enzyme 2 (ACE2) that is present in various types of cells including type 2 alveolar cells of lungs, stratified epithelial cells of the tongue, oral mucosa, and esophagus; columnar epithelial cells of ileum and colon, and myocardial cells Further, to enter a cell, viral S (spike) protein should be primed by host cell serine protease TMPRSS2 [5, 6]. COVID-19 spreads very fast crossing the borders to other countries, and on 11 March, the WHO has declared COVID-19 as a pandemic [7]

Till to date, there is no proven effective treatment for COVID-19, though dozens of existing compounds were suggested to be tested. A mega-trial on thousands of COVID-19 confirmed cases, which is called Solidarity, is recently underway to test four most promising compounds or combinations of compounds [8].

Around $15 \%$ of COVID-19 patients will fall into a severe state that makes hospitals become overwhelmed [8], so that many patients are neglected and cannot get appropriate treatment. Severe cases are mostly due to cytokine storms, which may lead to multiple organ failure and death [9], and might be managed by anti-inflammatory agents. One of the anti-inflammatory agents is a certain kind of stem cells, namely mesenchymal stem cells.

The main aim of this review is to present a brief outline of the properties of stem cells, general properties of mesenchymal stem cells, requirement of mesenchymal stem cell use in patients, the theoretical justification of mesenchymal stem cell use in COVID-19, and various published results and on-going clinical trials on mesenchymal stem cell use in COVID-19 to prevent or modulate severe COVID-19.
For this review, we searched various databases, i.e. Pubmed, Science Direct, Springer, and WHO website using keywords: "mesenchymal stem cells" and "COVID-19" at 7 May 2020, without time limits. Only English literatures were used. In addition, mesenchymal stem cell and COVID-19 related articles that were found during the writing of this article were included.

\section{The properties of stem cells}

Stem cells are the origin of all other cells in the body, and have two main capacities i.e. self-renewal and differentiation. According to the source, there are two main types of natural stem cells, i.e. embryonic and adult stem cells. Adult stem cells are more preferred, as their use is not restricted by ethical problems [10], and usually does not cause teratoma as the use of embryonic stem cells.

One type of adult stem cells that are widely used is the mesenchymal stem cell. Mesenchymal stem cells (MSCs) can be isolated easily from various tissues, including bone marrow [11], adipose tissue [12] umbilical cord [13], dental pulp [14], etc. Bone marrow MSCs were the first studied, followed by adipose tissue, umbilical cord, and various other tissues. MSCs from various sources show similar properties but may have subtle differences that can be seen in different DNA methylation pattern [15].

General properties of mesenchymal stem cells

Mesenchymal stem cells should fulfil minimal requirements that were set by International Society for Cell Therapy (ISCT), i.e. their shape should be fibroblastic, they should adhere to plastic vessel where they were cultured and should have certain positive surface markers $>95 \%$, i.e. CD 73, CD 90 and CD105, and negative surface markers (CD11b, CD14, CD19, CD34, CD45, CD79a and HLA-DR) should be $<2 \%$. In addition, they should be able to differentiate into three lineages, i.e. into chondrocyte, osteocyte, and adipocyte lineages [16].

The acronym MSCs recently may stand for mesenchymal stem cells, mesenchymal stromal cells, multipotent stem cells, or medicinal signaling cells. The ISCT, which is now broadened to the International Society for Cell and Gene Therapy, has formed an MSC committee that supports the use of the acronym MSCs as mesenchymal stem cells with certain requirements. The requirements include: the naming should be followed by an explanation of the tissue source, stemness should be proven in vitro and in vivo, and functional assays are needed to demonstrate MSC properties that are related to the intended therapeutic use of the MSCs [17]. 
MSC properties that are related to therapeutic use are secretion of trophic factors that may help in regeneration of injured tissue/organ, immunomodulation and promotion of angiogenesis. The assays to prove those properties, which are recommended by the ISCT's MSC committee, include quantitative RNA analysis of a certain gene, flow cytometry to prove the presence of surface markers, MSC secretome protein analysis, and characterization of MSC exosomes and their contents including microRNAs (miRNAs) [17].

\section{Requirement of mesenchymal stem cell use in patients}

To be used in patients, US Food and Drug Administration (FDA) has set a regulation that MSC production should be done in a current Good Manufacturing Practice (cGMP) facility to ensure that the product is safe and sterile, and following current Good Tissue Practice (cGTP) to prevent transmission of diseases from donors. In addition, various additional testing, including sterility, mycoplasma and endotoxin test should be conducted [18], and when post-thawed MSCs are used, viability should be $\geq 70 \%$ (FDA) or $\geq 80 \%$ (European Medicines Agency [EMA]) [19, 20]. To prevent zoonotic infectious agents and immune reaction due to xeno-material use, animal free material usage is encouraged, and to ensure efficacy, early passage use (passage-3 to passage-7) is recommended [20].

\section{Theoretical justification of stem cell use in COVID-19}

In severe COVID-19, patients may develop a severe inflammatory reaction and cytokine storm that causes acute respiratory distress syndrome (ARDS) and/or multiple organ failure, which finally leads to death [9]. Various studies showed the safety and efficacy of mesenchymal stem cells either against various inflammatory conditions, such as diseases with underlying inflammatory reactions, or conditions that needs immunomodulation [21]. Mesenchymal stem cells are immune-privileged as they have very few or negative class II human leucocyte antigen (HLA-II/HLA-DR)/major histocompatibility complex (MHC) class II, and co-stimulatory CD80 and CD86 molecules that are required for T-lymphocyte activation, so that allogeneic MSCs might not be rejected. They also have immunosuppressant and antiinflammatory properties. MSCs are attracted to site of inflammation, where they interact with immune cells and cause a shift in cytokine profile from inflammatory to anti-inflammatory profile [22]. Moreover, MSCs communicate with cells in injured tissues and secrete trophic factors that are needed for tissue repair [23]. Therefore, it is supposed that MSCs may prevent or modulate severe inflammatory reactions, and may promote repair in the injured lung due to COVID-19. However, there are some matters that need to be solved, such as the dose and route of administration and tissue source of the MSCs.

\section{MSCs against various inflammatory or autoimmune disease}

Various diseases have underlying inflammatory or autoimmune reaction, such as inflammatory bowel disease in the form of perianal fistula in Crohn's disease and ulcerative colitis; multiple sclerosis, systemic lupus erythematosus, graft versus host disease, inflammatory lung disease, type- 1 and type- 2 diabetes mellitus, etc. MSC immunomodulation properties have been used to treat those diseases, using various MSC sources, various doses, and various route of administration with variable degrees of success, but showed no long lasting effect, as improvement is usually temporary and last between six months to one year. This temporary effect might be due to the characteristics of treated diseases that were mostly chronic in nature [24-26]. COVID-19 is not a chronic disease, thus the use of MSCs that is intended to alleviate the cytokine storm and inflammatory reaction at the moment is justified, as after the inflammation and cytokine storm subsided MSCs are not needed any more.

Most MSC therapy, which used hospital-based-laboratory grown MSCs, for graft versus host disease, showed good results, but a large phase III study, which used commercial industrial product $2 \times 10^{6}$ cells/kg body weight, twice a week for four weeks, failed to reach its primary clinical endpoint. This failure was supposed to be due to over-expanded MSCs that were directly used after thawing [27] Therefore, for COVID-19, the MSCs should meet the requirements that were set by US-FDA or EMA [18-20]. In addition, when cryopreserved MSCs were used, re-culture to regain their immunemodulatory property is recommended.

\section{Dose and route of administration}

Previous studies on MSC use in diseases with underlying inflammatory or autoimmune reactions showed that those studies used various MSC sources, doses and routes of administration [24-26]. Therefore, MSC use in COVID-19 might take advantage from the knowledge of optimal and safe doses of MSC from a certain source. As the use of MSCs is intended to alleviate ARDS due to cytokine storm, the optimal route is supposed to be intravenous. A tracing study in mice, which used in vivo imaging system, revealed that $24 \mathrm{~h}$ after injection, most of the MSCs will be trapped in the lungs (30-60\%), and liver (5-15\%) [28]. A study on the clinical trial. Gov from 2008 through 2018, which consisted of 914 MSC trials, showed that $43 \%$ used the intravenous (IV) route. From the 914 trials, 16 had published their results. Most of the 16 published results showed that improved outcomes were attained using minimal effective dose (MED) between 70-190 million MSCs/patient/dose for IV route. However, four trials, which reported a dose response data, showed a narrower MED of 100-150 million MSCs/patient, while higher or lower IV doses were less effective [29].

A more direct route, such as on site transplantation into the bronchial tree and alveoli, theoretically may place the MSCs in the real battle field, but the fact that in ARDS there is accumulation of proteinaceous and fibrin exudate inside alveoli, and abundant macrophages infiltrating air spaces [30], this approach may be counterproductive as the MSCs may stay in the lumen of bronchial tree and cannot reach the battle field. Moreover, vehicle solution to suspend the MSCs may prevent oxygenation in alveoli, and aggravate the condition.

\section{Tissue source of MSCs}

Immune modulation property of MSCs might cope with severe inflammatory reaction in the lungs or other affected organs, and may mitigate the cytokine storm. In addition, MSC capacity to secrete trophic factors may aid in regeneration of injured tissues/organs. MSCs can be taken from various tissues, but for immune-modulatory purposes, MSCs from bone marrow (BM-MSCs), adipose tissue (ATMSCs) and birth-related tissue, namely umbilical cord MSCs (UCMSCs), umbilical cord blood MSCs (UCB-MSCs) are usually used in clinical trials [31]. Therefore, the most appropriate source need to be determined. Autologous MSCs need to be isolated and cultured to attain a certain number that is needed, thus need time around three to four weeks to be ready. As COVID-19 patients with ARDS needs fast management, ready to use allogeneic MSCs are more appropriate.

Bone marrow MSCs are the first studied and used in many clinical trials, but bone marrow aspiration is painful and may pose risks to the donor. Moreover, a study reviewed the immune-modulatory properties of MSCs from various tissues and showed that AT-MSCs had stronger immune-modulatory property compared to BM-MSCs, while UC-MSCs were similar to BM-MSCs, in term of inhibiting CD4+/CD8+lymphocyte activation. In term of dendritic cell differentiation inhibition, AT-MSCs showed more profound effect compared to BM-MSCs, and in term of dendritic cell maturation inhibition, UC-MSCs were equal to BM-MSCs, but UC-MSCs showed stronger effect in reducing dendritic cell endocytotic ability compared to BM-MSCs. In term of cytokine release inhibition, UCBMSCs were the most potent [31]. However, the isolation of UCBMSCs is the most difficult compared to UC-MSCs or AT-MSCs. Therefore, studies are needed to determine the best tissue source of MSCs, the dose, repeat, and route of administration.

\section{Various on-going clinical trials on stem cell use in COVID-19 and} a published result

A search in WHO International Clinical Trials Registry Platform (ICTRP) [32] on 26th March 2020 for COVID-19 yielded 648 clinical trials, twenty-eight of which are using MSCs, MSC's product (exosome and conditioned medium) or MSCs combined with other type of therapy. The clinical trials were registered in ClinicalTrial. Gov (nine trials [clinical trial identifier: NCT]), and Chinese Clinical Trial Registry (nine teen Trials [clinical trial identifier: ChiCTR]); mostly were from China (twenty-six), one from Jordan and one from Brazil. Four out of the registered clinical trials in Chinese Clinical Trial Registry were cancelled by the investigator and one that was registered in clinical trial. Gov was withdrawn. Most of the clinical trials used UC-MSCs, and were mostly given by intravenous route. The dose was variable, and given once to five times. However, the age ranges of most trials were very broad (table 1). These broad age ranges and simple randomization may result in unequal baseline age characteristics, so that the control and treatment group will not be comparable. 
Table 1: MSC clinical trials registered in WHO international clinical trials registry platform (ICTRP)

\begin{tabular}{|c|c|c|c|c|c|c|c|}
\hline $\begin{array}{l}\text { Referenc } \\
\text { es }\end{array}$ & $\begin{array}{l}\text { Clinical trial } \\
\text { identifier/regi } \\
\text { stration date }\end{array}$ & $\begin{array}{l}\text { Institution/ } \\
\text { Primary } \\
\text { sponsor }\end{array}$ & Title & $\begin{array}{l}\text { MSC source, } \\
\text { dose/vol, } \\
\text { route }\end{array}$ & $\begin{array}{l}\text { Study type/ } \\
\text { design/retrospe } \\
\text { ctive-prospectice }\end{array}$ & $\begin{array}{l}\text { Groups/Tar } \\
\text { get size/age } \\
\text { range }\end{array}$ & Status \\
\hline 32 & $\begin{array}{l}\text { ChiCTR2000030 } \\
116 / 23 \mathrm{Feb} \\
2020\end{array}$ & $\begin{array}{l}\text { The First } \\
\text { Affiliated } \\
\text { Hospital of } \\
\text { Nanchang } \\
\text { University, } \\
\text { Nanchang, } \\
\text { Jiangxi, China }\end{array}$ & $\begin{array}{l}\text { Safety and effectiveness of } \\
\text { human umbilical cord } \\
\text { mesenchymal stem cells in } \\
\text { the treatment of acute } \\
\text { respiratory distress } \\
\text { syndrome of severe novel } \\
\text { coronavirus pneumonia } \\
\text { (COVID-19) }\end{array}$ & $\begin{array}{l}\text { UC-MSC, } \\
\text { NR/NR, IV }\end{array}$ & $\begin{array}{l}\text { Intervention, dose } \\
\text { comparison }\end{array}$ & $\begin{array}{l}2 \text { groups: } 16 \\
18-75 y\end{array}$ & $\begin{array}{l}\text { Recruitin } \\
\text { g }\end{array}$ \\
\hline 32 & $\begin{array}{l}\text { NCT04269525/ } \\
7 \text { Feb } 2020\end{array}$ & $\begin{array}{l}\text { ZhiYong Peng, } \\
\text { Zhong Nan } \\
\text { Hospital, } \\
\text { Wuhan } \\
\text { University, } \\
\text { Wuhan, Hubei, } \\
\text { China }\end{array}$ & $\begin{array}{l}\text { Clinical Research } \\
\text { Regarding the availability } \\
\text { and safety of UC-MSCs } \\
\text { treatment for Serious } \\
\text { Pneumonia and Critical } \\
\text { Pneumonia Caused by the } \\
\text { 2019-nCOV Infection }\end{array}$ & $\begin{array}{l}\text { UC-MSC, } 10 \mathrm{x} \\
10^{7} / 150 \mathrm{ml} \\
\text { IV d-1-3-5-7 }\end{array}$ & $\begin{array}{l}\text { Intervention, } \\
\text { Phase 2, open } \\
\text { label }\end{array}$ & $\begin{array}{l}1 \text { group: } 10 \\
18-75 \mathrm{y}\end{array}$ & $\begin{array}{l}\text { Recruitin } \\
\mathrm{g}\end{array}$ \\
\hline 32 & $\begin{array}{l}\text { ChiCTR2000030 } \\
138 / 24 \mathrm{Feb} \\
2020\end{array}$ & $\begin{array}{l}\text { Chinese PLA } \\
\text { General Hospital, } \\
\text { Hainan Medical } \\
\text { University, } \\
\text { Beijing, China }\end{array}$ & $\begin{array}{l}\text { Clinical Trial for Human } \\
\text { Mesenchymal Stem Cells in } \\
\text { the Treatment of Severe } \\
\text { Novel Coronavirus } \\
\text { Pneumonia (COVID-19) }\end{array}$ & $\begin{array}{l}\text { UC-MSC, } \\
\text { NR/NR, IV }\end{array}$ & $\begin{array}{l}\text { Intervention, } \\
\text { phase 2, parallel, } \\
\text { randomized, } \\
\text { double-blind }\end{array}$ & $\begin{array}{l}2 \text { groups: Tr: } \\
30 \\
\text { C: } 30 \\
16-75 y\end{array}$ & $\begin{array}{l}\text { Not } \\
\text { Recruitin } \\
\text { g }\end{array}$ \\
\hline 32 & $\begin{array}{l}\text { NCT04273646/ } \\
14 \text { Feb } 2020\end{array}$ & $\begin{array}{l}\text { Wuhan Union } \\
\text { Hospital, China }\end{array}$ & $\begin{array}{l}\text { Clinical Study of Human } \\
\text { Umbilical Cord } \\
\text { Mesenchymal Stem Cells in } \\
\text { the Treatment of Novel } \\
\text { Coronavirus Severe } \\
\text { Pneumonia }\end{array}$ & $\begin{array}{l}\text { UC-MSC, } 5 \mathrm{x} \\
10^{6} / \mathrm{kg} \\
\mathrm{BW} / \mathrm{NR}, 4 \mathrm{x}\end{array}$ & $\begin{array}{l}\text { Intervention, } \\
\text { randomized, } \\
\text { parallel }\end{array}$ & $\begin{array}{l}2 \text { groups: Tr: } \\
24, \text { C: } 24 \\
18-65 y\end{array}$ & $\begin{array}{l}\text { Not } \\
\text { recruitin } \\
\text { g }\end{array}$ \\
\hline 32 & $\begin{array}{l}\text { ChiCTR2000030 } \\
300 / 28 \mathrm{Feb} \\
2020\end{array}$ & $\begin{array}{l}\text { Nanjing Second } \\
\text { Hospital, } \\
\text { Nanjingy, } \\
\text { Jiangsu, China }\end{array}$ & $\begin{array}{l}\text { Umbilical cord } \\
\text { mesenchymal stem cells } \\
\text { for the treatment of } \\
\text { patients at high risk of } \\
\text { novel coronavirus } \\
\text { pneumonia (COVID-19): a } \\
\text { single-center, prospective, } \\
\text { open clinical study }\end{array}$ & $\begin{array}{l}\text { UC-MSC, } \\
\text { NR/NR, NR }\end{array}$ & $\begin{array}{l}\text { Intervention, } \\
\text { Phase 1, case } \\
\text { series }\end{array}$ & $\begin{array}{l}1 \text { group: } 9 \\
18-75 \mathrm{y}\end{array}$ & $\begin{array}{l}\text { Canc by } \\
\text { the invest }\end{array}$ \\
\hline 32 & $\begin{array}{l}\text { NCT04252118/ } \\
27 \text { Jan } 2020\end{array}$ & $\begin{array}{l}\text { Beijing } 302 \\
\text { Hospital, China } \\
\text { (multi center) }\end{array}$ & $\begin{array}{l}\text { Safety and Efficiency of } \\
\text { Mesenchymal Stem Cell } \\
\text { in Treating Pneumonia } \\
\text { Patients Infected With } \\
2019 \text { Novel Coronavirus }\end{array}$ & $\begin{array}{l}\text { MSC, 3x } \\
10^{7} / \mathrm{NR}, \mathrm{IV} d- \\
0-3-6\end{array}$ & $\begin{array}{l}\text { Intervention, } \\
\text { phase 1, parallel, } \\
\text { non-randomized }\end{array}$ & $\begin{array}{l}2 \text { groups: Tr: } \\
\text { 10, C: } 10 \\
18-70 \mathrm{y}\end{array}$ & $\begin{array}{l}\text { Recruitin } \\
\mathrm{g}\end{array}$ \\
\hline 32 & $\begin{array}{l}\text { NCT04276987/ } \\
16 \text { Feb } 2020\end{array}$ & $\begin{array}{l}\text { Ruijin Hospital, } \\
\text { China }\end{array}$ & $\begin{array}{l}\text { A Pilot Clinical Study on } \\
\text { Aerosol Inhalation of the } \\
\text { Exosomes Derived From } \\
\text { Allogenic Adipose } \\
\text { Mesenchymal Stem Cells in } \\
\text { the Treatment of Severe } \\
\text { Patients With Novel } \\
\text { Coronavirus Pneumonia }\end{array}$ & $\begin{array}{l}\text { Allo-AT-MSC } \\
\text { exosome, } 2 \mathrm{x} \\
10^{8} \text { nano } \\
\text { vesicles } / 3 \mathrm{ml} \text {, } \\
\text { aerosol } \\
\text { inhalation } \\
\text { d1-2-3-4-5 }\end{array}$ & $\begin{array}{l}\text { Intervention, } \\
\text { phase } 1\end{array}$ & $\begin{array}{l}1 \text { group: } 30 \\
18-75 y\end{array}$ & $\begin{array}{l}\text { Not } \\
\text { recruitin } \\
\mathrm{g}\end{array}$ \\
\hline 32 & $\begin{array}{l}\text { ChiCTR2000030 } \\
\text { 484/3 March } \\
2020\end{array}$ & $\begin{array}{l}\text { Hubei Shiyan } \\
\text { Taihe hospital, } \\
\text { Shiyan, Hubei, } \\
\text { China }\end{array}$ & $\begin{array}{l}\text { HUMSCs and Exosomes } \\
\text { Treating Patients with } \\
\text { Lung Injury following } \\
\text { Novel Coronavirus } \\
\text { Pneumonia (COVID-19) }\end{array}$ & $\begin{array}{l}\text { UC-MSC } 5 \mathrm{x} \\
10^{7} / \mathrm{NR}, \mathrm{IV}- \\
1 \mathrm{x} / \mathrm{wk}- \\
2 \mathrm{x}=1 \mathrm{Co}, \\
\text { exosome } 180 \\
\mathrm{mg} / \mathrm{NR}-\mathrm{IV} / \mathrm{d}- \\
7 \mathrm{~d}=1 \mathrm{C}\end{array}$ & $\begin{array}{l}\text { Intervention, } \\
\text { parallel }\end{array}$ & $\begin{array}{l}\text { MSC-1 C: } 30 \\
\text { MSC+exo 2C: } \\
30 \text { C: } 30 \\
\text { Age range NR }\end{array}$ & $\begin{array}{l}\text { Not } \\
\text { Recruitin } \\
\text { g }\end{array}$ \\
\hline 32 & $\begin{array}{l}\text { ChiCTR2000030 } \\
866 / 16 \text { March } \\
2020\end{array}$ & $\begin{array}{l}\text { The First } \\
\text { Hospital of } \\
\text { Changsha, } \\
\text { Changsa, } \\
\text { Hu'nan, China }\end{array}$ & $\begin{array}{l}\text { Open-label, observational } \\
\text { study of human umbilical } \\
\text { cord derived mesenchymal } \\
\text { stem cells in the treatment } \\
\text { of severe and critical } \\
\text { COVID-1 }\end{array}$ & $\begin{array}{l}\text { UC-MSC, } \\
\text { NR/NR, NR }\end{array}$ & Intervention & $\begin{array}{l}1 \text { group: } 30 \\
18-85 y\end{array}$ & $\begin{array}{l}\text { Recruitin } \\
\mathrm{g}\end{array}$ \\
\hline 32 & $\begin{array}{l}\text { ChiCTR2000030 } \\
835 / 15 \text { March } \\
2020\end{array}$ & $\begin{array}{l}\text { the 1st Affiliated } \\
\text { Hospital of } \\
\text { Xinxiang Medical } \\
\text { University, } \\
\text { Xinxiang, He'nan, } \\
\text { China }\end{array}$ & $\begin{array}{l}\text { Clinical study on the } \\
\text { efficacy of Mesenchymal } \\
\text { stem cells (MSC) in the } \\
\text { treatment of severe novel } \\
\text { coronavirus pneumonia } \\
\text { (COVID-19) }\end{array}$ & $\begin{array}{l}\text { UC-MSC IV d- } \\
0-3-6 . \text { Low } \\
\text { dose: } 10^{6} / \mathrm{kg} \\
\text { BW } 1.25 \mathrm{ml} \text {, } \\
\text { high dose: } \\
2 \times 10^{6} / \mathrm{kg} \\
\text { BW } / 2.5 \mathrm{ml}\end{array}$ & Intervention & $\begin{array}{l}2 \text { groups: } \\
\text { Low dose: } 10 \\
\text { High dose: } 10 \\
16-75 \text { y }\end{array}$ & $\begin{array}{l}\text { Recruitin } \\
\text { g }\end{array}$ \\
\hline 32 & $\begin{array}{l}\text { NCT04288102/ } \\
24 \text { Feb } 2020\end{array}$ & $\begin{array}{l}\text { Beijing } 302 \\
\text { Hospital, China, }\end{array}$ & $\begin{array}{l}\text { Prospective, Randomized, } \\
\text { Multi-center Phase } 2\end{array}$ & $\begin{array}{l}\text { MSC } \\
4 \times 10^{7} / \mathrm{NR}, \mathrm{IV},\end{array}$ & $\begin{array}{l}\text { Intervention, } \\
\text { phase } 1-2 \text {, }\end{array}$ & $\begin{array}{l}2 \text { groups: } \\
\text { Tr: } 60 \text {, }\end{array}$ & $\begin{array}{l}\text { Recruitin } \\
\mathrm{g}\end{array}$ \\
\hline
\end{tabular}




\begin{tabular}{|c|c|c|c|c|c|c|c|}
\hline & & multi center & $\begin{array}{l}\text { Clinical Trial of } \\
\text { Mesenchymal Stem Cell } \\
\text { (MSC) for the Treatment of } \\
\text { Severe Corona Virus } \\
\text { Disease } 2019 \text { (COVID-19) }\end{array}$ & d-0-3-6 & $\begin{array}{l}\text { randomized, } \\
\text { double blind, } \\
\text { parallel }\end{array}$ & $\begin{array}{l}\text { Placebo Cl: } \\
30 \\
18-70 \text { y }\end{array}$ & \\
\hline 32 & $\begin{array}{l}\text { NCT04313322/ } \\
15 \text { march } 2020\end{array}$ & $\begin{array}{l}\text { Stem Cells } \\
\text { Arabia, Jordan }\end{array}$ & $\begin{array}{l}\text { Treatment of COVID-19 } \\
\text { Patients Using Wharton's } \\
\text { Jelly-Mesenchymal Stem } \\
\text { Cells }\end{array}$ & $\begin{array}{l}\text { UC-MSC- } \\
10^{6} / \mathrm{kg} \\
\text { BW/25 ml, } \\
\text { IV-3x-d-0-3-6 }\end{array}$ & $\begin{array}{l}\text { Intervention, } \\
\text { phase } 1 \text {, open } \\
\text { label, } \\
\text { retrospective }\end{array}$ & $\begin{array}{l}1 \text { group: } 5 \\
\text { 18-NR years }\end{array}$ & $\begin{array}{l}\text { Recruitin } \\
\mathrm{g}\end{array}$ \\
\hline 32 & $\begin{array}{l}\text { ChiCTR2000030 } \\
944 / 18 \text { March } \\
2020\end{array}$ & $\begin{array}{l}\text { The 2nd } \\
\text { Affiliated } \\
\text { Hospital of } \\
\text { Nanchang } \\
\text { University, } \\
\text { Nanchang, } \\
\text { Jiangxi, China }\end{array}$ & $\begin{array}{l}\text { An open, multi-center, } \\
\text { control, exploratory } \\
\text { clinical study of human } \\
\text { NK cells and UC-MSCs } \\
\text { transplantation for } \\
\text { severe novel coronavirus } \\
\text { pneumonia }\end{array}$ & $\begin{array}{l}\text { NK cell+UC- } \\
\text { MSC-NR/NR, } \\
\text { NR }\end{array}$ & $\begin{array}{l}\text { Intervention, } \\
\text { phase 1, } \\
\text { randomized, } \\
\text { parallel, }\end{array}$ & $\begin{array}{l}2 \text { groups: } \\
\text { Tr: } 10 \\
\text { C: } 10,4-80 y\end{array}$ & $\begin{array}{l}\text { Not } \\
\text { Recruitin } \\
\text { g }\end{array}$ \\
\hline 32 & $\begin{array}{l}\text { ChiCTR2000030 } \\
224 / 26 \text { Feb } \\
2020\end{array}$ & $\begin{array}{l}\text { Union Hospital, } \\
\text { Tongji Med. } \\
\text { College, } \\
\text { Huazhong Univ. } \\
\text { of Science and } \\
\text { Technology, } \\
\text { Wuhan, Hubei, } \\
\text { China }\end{array}$ & $\begin{array}{l}\text { Clinical study of } \\
\text { mesenchymal stem cells } \\
\text { in treating severe novel } \\
\text { coronavirus pneumonia } \\
\text { (COVID-19) }\end{array}$ & $\begin{array}{l}\text { MSC, NR/NR, } \\
\text { NR }\end{array}$ & $\begin{array}{l}\text { Intervention, } \\
\text { parallel }\end{array}$ & $\begin{array}{l}\text { Cr.: } 8, \text { Cr C: } 8 \text {, } \\
\text { Se: } 8 \text {, Se C: } 8 \\
18-100 \text { y }\end{array}$ & $\begin{array}{l}\text { Canc by } \\
\text { the invest }\end{array}$ \\
\hline 32 & $\begin{array}{l}\text { ChiCTR2000029 } \\
\text { 569/4 Feb } 2020\end{array}$ & $\begin{array}{l}\text { Xiangyang 1st } \\
\text { People's } \\
\text { Hospital, } \\
\text { Xiangyang, } \\
\text { Hubei, China }\end{array}$ & $\begin{array}{l}\text { Safety and efficacy of } \\
\text { umbilical cord blood } \\
\text { mononuclear cells } \\
\text { conditioned medium in } \\
\text { the treatment of severe } \\
\text { and critically novel }\end{array}$ & $\begin{array}{l}\text { UCB-MNC- } \\
\text { CM, NR/NR, } \\
\text { NR }\end{array}$ & $\begin{array}{l}\text { Intervention, } \\
\text { parallel, } \\
\text { randomized, open } \\
\text { label, }\end{array}$ & $\begin{array}{l}2 \text { groups: } \\
\mathrm{Tr}=15 \\
\mathrm{C}=15,18-\mathrm{NR}\end{array}$ & $\begin{array}{l}\text { Not } \\
\text { recruitin } \\
\mathrm{g}\end{array}$ \\
\hline 32 & $\begin{array}{l}\text { ChiCTR2000030 } \\
173 / 24 \text { Feb } \\
2020\end{array}$ & $\begin{array}{l}\text { Hu'nan Yuanpin } \\
\text { Cell } \\
\text { Biotechnology } \\
\text { Co., Ltd, } \\
\text { Changsha, } \\
\text { Hu'nan, China }\end{array}$ & $\begin{array}{l}\text { Key techniques of } \\
\text { umbilical cord } \\
\text { mesenchymal stem cells } \\
\text { for the treatment of novel } \\
\text { coronavirus pneumonia } \\
\text { (COVID-19) and clinical } \\
\text { application demonstration }\end{array}$ & $\begin{array}{l}\text { UC-MSC, } \\
\text { NR/NR, NR }\end{array}$ & $\begin{array}{l}\text { Intervention, } \\
\text { parallel, } \\
\text { randomized }\end{array}$ & $\begin{array}{l}2 \text { groups: } \\
\operatorname{Tr}=30 \\
\mathrm{C}=30,18- \\
\text { 70years }\end{array}$ & $\begin{array}{l}\text { Not } \\
\text { Recruitin } \\
\text { g }\end{array}$ \\
\hline 32 & $\begin{array}{l}\text { ChiCTR2000029 } \\
606 / 7 \text { Feb } 2020\end{array}$ & $\begin{array}{l}\text { The First } \\
\text { Affiliated } \\
\text { Hospital, } \\
\text { College of } \\
\text { Medicine, } \\
\text { Zhejiang } \\
\text { University, } \\
\text { Hangzhou, } \\
\text { Zhejiang, China }\end{array}$ & $\begin{array}{l}\text { Clinical Study for Human } \\
\text { Menstrual Blood-derived } \\
\text { Stem Cells in the } \\
\text { Treatment of Acute Novel } \\
\text { Coronavirus Pneumonia } \\
\text { (COVID-19) }\end{array}$ & $\begin{array}{l}\text { Hu menstrual } \\
\text { blood } \\
\text { SC+artificial } \\
\text { liver, NR/NR, } \\
\text { IV }\end{array}$ & $\begin{array}{l}\text { Intervention, } \\
\text { parallel, open } \\
\text { label, randomized, } \\
\text { A=SC, B1= } \\
\text { artificial Liver, } \\
\text { B2= SC+artificial } \\
\text { liver }\end{array}$ & $\begin{array}{l}5 \text { groups: } \\
\text { Tr-A=18, Tr- } \\
B 1=10, \text { Tr- } \\
B 2=10, C-A= \\
15, C-B=10, \\
1-99 y\end{array}$ & $\begin{array}{l}\text { Recruitin } \\
\mathrm{g}\end{array}$ \\
\hline 32 & $\begin{array}{l}\text { ChiCTR2000030 } \\
088 / 22 \mathrm{Feb} \\
2020\end{array}$ & $\begin{array}{l}\text { The Sixth } \\
\text { Medical Center } \\
\text { of PLA General } \\
\text { Hospital, } \\
\text { Beijing, China }\end{array}$ & $\begin{array}{l}\text { Umbilical cord Wharton's } \\
\text { Jelly derived } \\
\text { mesenchymal stem cells } \\
\text { in the treatment of severe } \\
\text { novel coronavirus } \\
\text { pneumonia (COVID-19) }\end{array}$ & $\begin{array}{l}\text { UC-MSC, } \\
10^{6} / \mathrm{kg} \\
\text { BW/40 ml, IV }\end{array}$ & $\begin{array}{l}\text { Intervention, } \\
\text { parallel, } \\
\text { randomized }\end{array}$ & $\begin{array}{l}2 \text { groups: } \mathrm{Tr}= \\
20 \\
\mathrm{C}=20 \\
18-80 \mathrm{y}\end{array}$ & $\begin{array}{l}\text { Not } \\
\text { Recruitin } \\
\text { g }\end{array}$ \\
\hline 32 & $\begin{array}{l}\text { ChiCTR2000029 } \\
990 / 18 \text { Feb } \\
2020\end{array}$ & $\begin{array}{l}\text { institute of basic } \\
\text { medicine, } \\
\text { Chinese } \\
\text { Academy of } \\
\text { medical sciences, } \\
\text { Beijing, China }\end{array}$ & $\begin{array}{l}\text { Clinical trials of } \\
\text { mesenchymal stem cells } \\
\text { for the treatment of } \\
\text { pneumonitis caused by } \\
\text { novel coronavirus } \\
\text { (COVID-19) }\end{array}$ & $\begin{array}{l}\text { MSC, NR/NR. } \\
\text { NR }\end{array}$ & $\begin{array}{l}\text { Intervention, } \\
\text { parallel, } \\
\text { randomized }\end{array}$ & $\begin{array}{l}2 \text { groups: } \mathrm{Tr}= \\
60, \mathrm{C}=60 \\
\text { Age range NR }\end{array}$ & $\begin{array}{l}\text { Recruitin } \\
\text { g, partly } \\
\text { reported }\end{array}$ \\
\hline 32 & $\begin{array}{l}\text { ChiCTR2000030 } \\
020 / 20 \mathrm{Feb} \\
2020\end{array}$ & $\begin{array}{l}\text { Second Hospital } \\
\text { of University of } \\
\text { South China, } \\
\text { Hengyang, } \\
\text { Hu'nan, China }\end{array}$ & $\begin{array}{l}\text { The clinical application } \\
\text { and basic research } \\
\text { related to mesenchymal } \\
\text { stem cells to treat novel } \\
\text { coronavirus pneumonia } \\
\text { (COVID-19) }\end{array}$ & $\begin{array}{l}\text { MSC, NR/NR, } \\
\text { NR }\end{array}$ & $\begin{array}{l}\text { Intervention, } \\
\text { sequential, non- } \\
\text { randomized }\end{array}$ & $\begin{array}{l}1 \text { group: } 20 \\
\text { (case series), } \\
18-70 \mathrm{y}\end{array}$ & $\begin{array}{l}\text { Recruitin } \\
\mathrm{g}\end{array}$ \\
\hline 32 & $\begin{array}{l}\text { ChiCTR2000030 } \\
261 / 26 \text { Feb } \\
2020\end{array}$ & $\begin{array}{l}\text { Wuxi Fifth } \\
\text { People's } \\
\text { Hospital, } \\
\text { Jiangsu, China }\end{array}$ & $\begin{array}{l}\text { A study for the key } \\
\text { technology of } \\
\text { mesenchymal stem cells } \\
\text { exosomes atomization in } \\
\text { the treatment of novel } \\
\text { coronavirus pneumonia } \\
\text { (COVID-19) }\end{array}$ & $\begin{array}{l}\text { MSC- } \\
\text { exosome, } \\
\text { NR/NR, } \\
\text { aerosol } \\
\text { inhalation }\end{array}$ & $\begin{array}{l}\text { Intervention, } \\
\text { parallel, } \\
\text { randomized }\end{array}$ & $\begin{array}{l}2 \text { groups: } \mathrm{Tr}= \\
13, \mathrm{C}=13 \\
\text { Age range NR }\end{array}$ & $\begin{array}{l}\text { Not } \\
\text { Recruitin } \\
\text { g }\end{array}$ \\
\hline 32 & $\begin{array}{l}\text { ChiCTR2000029 } \\
580 / 5 \text { Feb } 2020\end{array}$ & $\begin{array}{l}\text { Department of } \\
\text { Hematology, } \\
\text { Tongji Hospital, }\end{array}$ & $\begin{array}{l}\text { Severe novel coronavirus } \\
\text { pneumonia (COVID-19) } \\
\text { patients treated with }\end{array}$ & $\begin{array}{l}\text { MSC+ruxoliti } \\
\text { nib, NR/NR, } \\
\text { NR }\end{array}$ & $\begin{array}{l}\text { Intervention, } \\
\text { parallel, } \\
\text { randomized, }\end{array}$ & $\begin{array}{l}2 \text { groups: } \mathrm{Tr}= \\
35, \mathrm{C}=35 \\
\text { (routine }\end{array}$ & $\begin{array}{l}\text { Recruitin } \\
\mathrm{g}\end{array}$ \\
\hline
\end{tabular}




\begin{tabular}{|c|c|c|c|c|c|c|c|}
\hline & & $\begin{array}{l}\text { Tongji Medical } \\
\text { College, } \\
\text { Huazhong } \\
\text { University of } \\
\text { Science and } \\
\text { Technology, } \\
\text { Wuhan, Hubei, } \\
\text { China }\end{array}$ & $\begin{array}{l}\text { ruxolitinib in } \\
\text { combination with } \\
\text { mesenchymal stem cells: } \\
\text { a prospective, single } \\
\text { blind, randomized } \\
\text { controlled clinical trial }\end{array}$ & & single blind & $\begin{array}{l}\text { treatment) } \\
18-75 \mathrm{y}\end{array}$ & \\
\hline 32 & $\begin{array}{l}\text { ChiCTR2000029 } \\
817 / 14 \text { Feb } \\
2020\end{array}$ & $\begin{array}{l}\text { Guangzhou } \\
\text { reborn health } \\
\text { management } \\
\text { consultation co., } \\
\text { LTD, } \\
\text { Guangzhou, } \\
\text { Guangdong, } \\
\text { China }\end{array}$ & $\begin{array}{l}\text { Clinical Study of Cord } \\
\text { Blood NK Cells Combined } \\
\text { with Cord Blood } \\
\text { Mesenchymal Stem Cells } \\
\text { in the Treatment of Acute } \\
\text { Novel Coronavirus } \\
\text { Pneumonia (COVID-19) }\end{array}$ & $\begin{array}{l}\text { UCB- } \\
\text { NK+UCB- } \\
\text { MSC, } \\
5 \times 10^{9}+5 \times 10^{9} \\
-5 \times \text { E2d } \\
3 \times 10^{9}+3 \times 10^{9} \\
-3 \times \text { E2d } \\
3 \times \\
10^{9}+3 \times 10^{9}- \\
1 \times / w k \\
/ N R, ~ I V\end{array}$ & $\begin{array}{l}\text { Intervention, } \\
\text { parallel, } \\
\text { randomized, open } \\
\text { label }\end{array}$ & $\begin{array}{l}3 \text { groups: } \\
\text { HD }=20, \\
\text { conventional } \\
\text { dose }=20, \\
\text { preventive } \\
\text { dose }=20,18- \\
\text { NR years }\end{array}$ & $\begin{array}{l}\text { Canc by } \\
\text { the invest }\end{array}$ \\
\hline 32 & $\begin{array}{l}\text { ChiCTR2000029 } \\
816 / 14 \text { Feb } \\
2020\end{array}$ & $\begin{array}{l}\text { Guangzhou } \\
\text { reborn health } \\
\text { management } \\
\text { consultation co., } \\
\text { LTD, Guangzhou, } \\
\text { Guangdong, } \\
\text { China }\end{array}$ & $\begin{array}{l}\text { Clinical Study of Cord } \\
\text { Blood Mesenchymal Stem } \\
\text { Cells in the Treatment of } \\
\text { Acute Novel Coronavirus } \\
\text { Pneumonia (COVID-19) }\end{array}$ & $\begin{array}{l}\text { UCB-MSC, } \\
\text { NR/NR, IV }\end{array}$ & $\begin{array}{l}\text { Intervention, } \\
\text { parallel, } \\
\text { randomized, open } \\
\text { label }\end{array}$ & $\begin{array}{l}2 \text { groups: } \mathrm{Tr}= \\
30, \mathrm{C}=30 \\
18-\mathrm{NR} \text { years }\end{array}$ & $\begin{array}{l}\text { Canc by } \\
\text { the invest }\end{array}$ \\
\hline 32 & $\begin{array}{l}\text { NCT04293692/ } \\
24 \text { Feb 2020- } \\
\text { 3March } 2020\end{array}$ & $\begin{array}{l}\text { Puren Hospital } \\
\text { Affiliated to } \\
\text { Wuhan } \\
\text { University of } \\
\text { Science and } \\
\text { Technology, } \\
\text { Wuhan, Hubei, } \\
\text { China }\end{array}$ & $\begin{array}{l}\text { Human Umbilical Cord } \\
\text { Mesenchymal Stem Cells } \\
\text { Treatment for } \\
\text { Pneumonia Patients } \\
\text { Infected by } 2019 \text { Novel } \\
\text { Coronavirus }\end{array}$ & $\begin{array}{l}\text { UC-MSC, } \\
0.5 \times 10^{6} / \mathrm{kg} \\
\text { BW } / 100 \text { ml- } \\
\text { IV, d-1-3-5-7 }\end{array}$ & $\begin{array}{l}\text { Intervention, } \\
\text { parallel, } \\
\text { randomized, } \\
\text { masking triple }\end{array}$ & $\begin{array}{l}2 \text { groups: } \\
\mathrm{Tr}=0 \\
\mathrm{C}=0,18-75 \mathrm{y}\end{array}$ & $\begin{array}{l}\text { Withdra } \\
\text { wn }\end{array}$ \\
\hline 32 & $\begin{array}{l}\text { NCT0 } 4302519 / \\
27 \text { Feb-10 } \\
\text { March } 2020\end{array}$ & $\begin{array}{l}\text { Research office } \\
\text { of wuhan renmin } \\
\text { university/CAR- } \\
\mathrm{T} \text { (Shanghai) } \\
\text { Biotechnology } \\
\text { Co., Ltd. } \\
\text { Shanghai, China }\end{array}$ & $\begin{array}{l}\text { Clinical Study of Novel } \\
\text { Coronavirus Induced } \\
\text { Severe Pneumonia } \\
\text { Treated by Dental Pulp } \\
\text { Mesenchymal Stem Cells }\end{array}$ & $\begin{array}{l}\text { Dental pulp } \\
\text { MSC, } 10^{6} / \mathrm{kg} \\
\text { BW/50 ml } \\
\text { saline-cell, } 50 \\
\text { ml saline, IV, } \\
\text { d1-3-7 }\end{array}$ & $\begin{array}{l}\text { Intervention } \\
\text { Phase 1, open } \\
\text { label }\end{array}$ & $\begin{array}{l}1 \text { group: } 24 \\
18-75 y\end{array}$ & $\begin{array}{l}\text { Not } \\
\text { recruitin } \\
\mathrm{g}\end{array}$ \\
\hline 32 & $\begin{array}{l}\text { NCT04315987/ } \\
18-20 \text { March } \\
2020\end{array}$ & $\begin{array}{l}\text { Azidus Brasil/ } \\
\text { Hospital Vera } \\
\text { Cruz São Paulo, } \\
\text { Brazil }\end{array}$ & $\begin{array}{l}\text { Exploratory Clinical Study } \\
\text { to Assess the Efficacy of } \\
\text { Mesenchymal Stem Cell } \\
\text { NestCell@ to Treat } \\
\text { Patients With Severe } \\
\text { COVID-19 Pneumonia }\end{array}$ & $\begin{array}{l}\text { MSC } \\
\text { (NestCell }(- \\
\text { Cellavita), } \\
2 \times 10^{7} / N R, ~ I V, \\
\text { d-1-3-5-(7) }\end{array}$ & $\begin{array}{l}\text { Intervention, } \\
\text { Phase } 1 \text {, open } \\
\text { label }\end{array}$ & $\begin{array}{l}1 \text { group: } 66 \\
\text { 18-NR years }\end{array}$ & $\begin{array}{l}\text { Not } \\
\text { recruitin } \\
\text { g }\end{array}$ \\
\hline 32 & $\begin{array}{l}\text { ChiCTR2000031 } \\
\text { 139/22 Maret } \\
2020\end{array}$ & $\begin{array}{l}\text { Wuhan Jinyintan } \\
\text { Hospital (Wuhan } \\
\text { Infectious } \\
\text { Diseases } \\
\text { Hospital), } \\
\text { Wuhan, Hubei, } \\
\text { China }\end{array}$ & $\begin{array}{l}\text { Safety and Effectiveness } \\
\text { of Human embryonic } \\
\text { stem cell-derived M cells } \\
\text { (CAStem) for Pulmonary } \\
\text { Fibrosis Correlated with } \\
\text { novel coronavirus } \\
\text { pneumonia(COVID-19) }\end{array}$ & $\begin{array}{l}\text { ESC derived } \\
\text { M cells } \\
(\text { CAStem), } \\
3 \times 10^{6} / \mathrm{kg} \\
\mathrm{BW} / \mathrm{NR}, \mathrm{IV}, \\
2-3 \times(1 \mathrm{wk} \\
\text { apart) }\end{array}$ & $\begin{array}{l}\text { Intervention, } \\
\text { sequential }\end{array}$ & $\begin{array}{l}1 \text { group: } 20 \\
\text { (case series) } \\
18-80 \mathrm{y}\end{array}$ & $\begin{array}{l}\text { Recruitin } \\
\mathrm{g}\end{array}$ \\
\hline
\end{tabular}

ChiCTR= Chinese Clinical Trial Registry, UC-MSC $=$ umbilical cord-MSC, NR= not reported, IV= intravenous, NCT= ClinicalTrials. gov, $d-=$ day-, Tr= treatment, $\mathrm{C}=$ control, $\mathrm{MSC}=$ mesenchymal stem cell, Allo= allogeneic, $\mathrm{AT}-\mathrm{MSC}=$ adipose tissue $\mathrm{MSC}, \mathrm{Co}=\mathrm{course}, \mathrm{BW}=\mathrm{body}$ weight, $\mathrm{Canc}=\mathrm{cancelled}$, invest= investigator, $\mathrm{NK}$ cell= natural killer cell, $\mathrm{Cr}=$ critically severe, $\mathrm{Se}=$ severe, $\mathrm{UCB}=$ umbilical cord blood, $\mathrm{MNC}=\mathrm{mononuclear}$ cell, $\mathrm{CM}=$ conditioned medium, hu= human, $\mathrm{SC}=$ stem cell, $\mathrm{E} 2 \mathrm{~d}=$ every $2 \mathrm{~d}$, wk= week, $\mathrm{ESC}=$ Embryonic stem cell

One of the clinical trials that used MSCs for COVID-19 pneumonia (ChiCTR2000029990), which intended to enroll 60 MSC treated subjects and 60 controls (table 1), has published part of the study. This report by Leng et al. [33] enrolled seven MSC treated subjects and three controls and showed promising results in term of clinical recovery and serum cytokine profile. The MSCs were given only once intravenously, $10^{6}$ cells $/ \mathrm{kg}$ body weight; all of the critically severe, severe, and common type of COVID-19 in the treatment group recovered, while none of the control group, which were all of the severe type, recovered. In the control group, one died, one developed ARDS, and one remains stable. However, the treatment and control groups were unequal in term of their age and severity of the disease. The treatment group consisted of one critically severe, four severe and two common, while the control group consisted of three severe types of COVID-19, which means that the treatment group was more variable compared to the control group. Moreover, the ages of patients were not equal; the control group, who died and the one that developed ARDS, were much older than in the treatment group. The oldest patient in the treatment group, who had a critically severe type, was $65 \mathrm{y}$ old, while the patients in the control group, who died and developed ARDS, were 75 and $74 \mathrm{y}$ old, respectively [33]. A study on 1099 confirmed COVID-19 patients showed that subjects of $\geq 65$ y old were more prone to end in ICU, needed mechanical ventilation or death compared to those of at younger ages, which were $49.2 \%, 32,3,18.5$, and $0 \%$ for patients aged $\geq 65,50-64,15-49$, and $0-14$ y old, respectively [34]. Another 
study showed that of 168 deaths due to confirmed COVID-19, 161 patients were older than 50 y old, and median age was 70 (interquartile range $=64-78$ ) [35]. In addition, the MSCs in Leng et al. study was certified by Chinese FDA (authorization number: 2004L04792, 2006L01037, CXSB1900004), but the study did not mention the tissue source, method of isolation and culture, passage or cumulative population doublings, and properties of the MSCs. They only mention that the MSCs were ACE2 and TMPRSS2 negative, thus could not be infected by the virus, [33]; ACE2 low/negative expression is a property that is supposedly shared by most stem cells, which are undifferentiated cells, as ACE2 expression depends on cell differentiation state [36]. The information concerning tissue source, method of isolation and culture, passage or cumulative population doubling are necessary, as they may interfere with MSC quality and properties [15]. The MSCs in Leng et al. study were apparently derived from the umbilical cord, as stated by Zhao that MSCs with Chinese FDA authorization number 2004L04792, 2006L01037, CXSB1900004 were derived from umbilical cords that were obtained from two healthy donors and processed in a cGMP facility. The cord tissues were processed using collagenase 1 and trypsin, and cultured using fetal bovine serum-containing medium, and cells from passage- 6 were used for transplantation [37]

Further, a case report on COVID-19, which was published in Chinaxiv. org, showed recovery of a critically ill 65-year-old female COVID-19 patient, after three sessions of allogeneic human UC-MSC ( $5 \times 10^{7}$ cells) and thymosin $\alpha 1$ infusion that were given three days apart. Initially, the patient got glucocorticoid, antiviral and antibiotic Then, thymosin $\alpha 1$ was given to modulate immune cell ratio six days before UC-MSC, as immune/inflammation-related hemolysis was suspected due to failure to increase red blood cell count/haemoglobin concentration after blood transfusion. Before UC-MSC administration, the patient was in ICU and confirmed as critically ill COVID-19 with severe pneumonia, respiratory distress, liver injury, type- 2 diabetes, hypertension, electrolyte imbalance, and acute gastrointestinal bleeding (possibly due to glucocorticoid therapy to alleviate inflammatory reaction), thus glucocorticoid was stopped before UC-MSC administration. Two days after the last session of UC-MSC and thymosin $\alpha 1$, the patient was out of ICU, clinical signs and laboratory indices were normal, and swab test was reported negative and remained negative $2 \mathrm{~d}$ later [38].

Initial clinical trial results triggered big pharmaceuticals to develop clinical trials using their commercial MSC products and attempted to get US FDA approval for emergency Investigational New Drug (IND) application. 'Mesoblast Limited' got an approval on 5 April 2020 for Ryoncil (Remestemcel-L) to be used in COVID-19 ARDS. They conducted case series, and claimed that $75 \%$ of the twelve patients, who were previously refractory to other experimental therapies, were free from ventilators within $10 \mathrm{~d}$, and overall, there was $83 \%$ survival after two intravenous infusion of Ryoncil. For comparison, Mesoblast used data from two major referral hospital networks in New York City, where $9 \%$ of 445 , and $12 \%$ of 320 ventilator dependent COVID-19 patients survived when treated with standard of care during March and April 2020 [39]. In the future, other MSC producing pharmaceutical companies like Athersys, 'Pluristem therapeutics' with its PLX cell product, Cynata with its Cymerus ${ }^{\text {TM }}$ platform, 'Lattice Biologics' with its AmnioBoost, 'Tianhe Stem Cell Biotechnologies' and ReeLabs are likely to pursue the same path as 'Mesoblast Limited'.

Finally, theoretically, MSC immunomodulation property might be beneficial to alleviate severe inflammation and cytokine storm, but immune suppression might also promote secondary infection Therefore, concomitant antibiotic use might be needed. An initial case report [38], case series [39] and a small clinical trial [33] seem to support the benefit of MSCs to cure severe COVID-19. However, those results should be interpreted cautiously, because there were severe and critically severe COVID-19 that were able to survive; so survival of the patients in the case report and case series might reflect the natural course of the disease that in some cases were not fatal. A study showed that cumulative risk to primary composite end-point events, which were admission to an intensive care unit (ICU), mechanical ventilation use, or death, among severe COVID-19 cases was $20.6 \%$ [34]; so, there is around $80 \%$ possibility that a severe case to be stable or finally recovered and cured. Moreover, the shift in pro-inflammatory to anti-inflammatory cytokine profile as reported by Leng et al. [33] might reflect the natural course of a disease recovery, as shift in cytokine profile also occurred in recovered patients without MSC therapy [40]. Therefore, though initial study results seem promising, more robust proof is needed, and the real prove should come from well design randomized clinical trials with enough participants, where randomization will assure equality between treatments and controls at baseline.

\section{CONCLUSION}

Several studies showed that MSCs seemed promising to alleviate inflammation and cytokine storm in severe COVID-19, but the results should be interpreted cautiously, and well design randomized clinical trials are needed to get a more robust prove.

\section{FUNDING}

Nil

\section{AUTHORS CONTRIBUTIONS}

All the authors have contributed equally.

\section{CONFLICT OF INTERESTS}

The authors declare that there is no conflict of interest.

\section{REFERENCES}

1. Ma J. Coronavirus: China's first confirmed Covid-19 case traced back to November 17. South China Morning Post. Available from:

https://www.scmp.com/news/china/society/article/3074991 /coronavirus-chinas-first-confirmed-covid-19-case-tracedback. [Last accessed on 25 Mar 2020]

2. WHO. Emergencies preparedness, response. Pneumonia of unknown cause-China. WHO; 2020. Available from: https://www.who.int/csr/don/05-january-2020-pneumoniaof-unkown-cause-china/en/. [Last accessed on 25 Mar 2020]

3. Zhu N, Zhang D, Wang W, Li X, Yang B, Song J, et al. A novel coronavirus from patients with pneumonia in China, 2019. N Engl J Med 2020;382:727-33.

4. 4WHO. Naming the coronavirus disease (Covid-19) and the virus that causes it. WHO; 2020. https://www.who.int/emergencies/diseases/novelcoronavirus-2019/technical-guidance/naming-thecoronavirus-disease-(covid-2019)-and-the-virus-that-causes-it. [Last accessed on 25 Mar 2020]

5. Hoffmann M, Kleine Weber H, Schroeder S, Kruger N, Herrler T, Erichsen S, et al. SARS-CoV-2 cell entry depends on ACE2 and TMPRSS2 and is blocked by a clinically proven protease inhibitor. Cell 2020;181:271-80.

6. $\mathrm{Xu} \mathrm{H}$, Zhong L, Deng J, Peng J, Dan $\mathrm{H}$, Zeng $\mathrm{X}$, et al. High expression of ACE2 receptor of $2019-\mathrm{nCoV}$ on the epithelial cells of oral mucosa. Int J Oral Sci 2020;12:8.

7. WHO. Virtual press conference on COVID-19. WHO; 2020 Available from: https://www.who.int/docs/defaultsource/coronaviruse/transcripts/who-audio-emergenciescoronavirus-press-conference-full-and-final11 mar2020.pdf?sfvrsn=cb432bb3_2. [Last accessed on 25 Mar 2020].

8. Kupferschmidt K, Cohen J. WHO launches global megatrial of the four most promising coronavirus treatments. Sciencemag; 2020. Available from: https://www.sciencemag.org/news/ 2020/03/who-launches-global-megatrial-four-mostpromising-coronavirus-treatments. [Last accessed on 25 Mar 2020].

9. Li X, Geng M, Peng Y, Meng L, Lu S. Molecular immune pathogenesis and diagnosis of COVID-19. J Pharm Anal 2020;10:102-8

10. Dominici M, Paolucci P, Conte P, Horwitz EM. Heterogeneity of multipotent mesenchymal stromal cells: from stromal cells to stem cells and vice versa. Transplantation 2009;87(9 Suppl):S36-42.

11. Dilogo IH, Mujadid F, Nurhayati RW, Kurniawan A. Evaluation of bone marrow-derived mesenchymal stem cell quality from 
patients with congenital pseudoarthrosis of the tibia. J Orthop Surg Res 2018;13:266.

12. Nofianti CE, Sari IN, Marlina, Novialdi, Pawitan JA. Temporary storage solution for adipose-derived mesenchymal stem cells. Stem Cell Investig 2018;5:19.

13. Smith JR, Pfeifer K, Petry F, Powell N, Delzeit J, Weiss ML. Standardizing umbilical cord mesenchymal stromal cells for translation to clinical use: a selection of GMP-compliant medium and a simplified isolation method. Stem Cells Int 2016;2016:6810980.

14. Fernandes TL, Cortez de Sant Anna JP, Frisene I, Gazarini JP, Gomes Pinheiro CC, Gomoll AH, et al. Systematic review of human dental pulp stem cells for cartilage regeneration. Tissue Eng Part B Rev 2020;26:1-12.

15. de Almeida DC, Ferreira MR, Franzen J, Weidner CI, Frobel J, Zenke $\mathrm{M}$, et al. Epigenetic classification of human mesenchymal stromal cells. Stem Cell Reports 2016;6:168-75.

16. Dominici M, Le Blanc K, Mueller I, Slaper Cortenbach I, Marini F, Krause D, et al. Minimal criteria for defining multipotent mesenchymal stromal cells. International Society for Cellular Therapy position statement. Cytotherapy 2006;8:315-7.

17. Viswanathan S, Shi Y, Galipeau J, Krampera M, Leblanc K, Martin I, et al. Mesenchymal stem versus stromal cells: international society for cell and gene therapy (ISCT) mesenchymal stromal cell committee position statement on nomenclature. Cytotherapy 2019;21:1019-24.

18. Mendicino M, Fan Y, Griffin D, Gunter KC, Nichols K. Current state of U. S. food and drug administration regulation for cellular and gene therapy products: potential cures on the horizon. Cytotherapy 2019;21:699-724.

19. Mendicino M, Bailey AM, Wonnacott K, Puri RK, Bauer SR. MSCbased product characterization for clinical trials: an FDA perspective. Cell Stem Cell 2014;14:141-5.

20. Guadix JA, Lopez Beas J, Clares B, Soriano Ruiz JL, Zugaza JL, Galvez Martin P. Principal criteria for evaluating the quality, safety and efficacy of hMSC-based products in clinical practice: current approaches and challenges. Pharmaceutics 2019;11:pii:E552.

21. Gao F, Chiu SM, Motan DA, Zhang Z, Chen L, Ji HL, et al. Mesenchymal stem cells and immunomodulation: current status and future prospects. Cell Death Dis 2016;7:e2062.

22. Andreeva E, Bobyleva P, Gornostaeva A, Buravkova L. Interaction of multipotent mesenchymal stromal and immune cells: bidirectional effects. Cytotherapy 2017;19:1152-66.

23. Hodgkinson CP, Bareja A, Gomez JA, Dzau VJ. Emerging concepts in paracrine mechanisms in regenerative cardiovascular medicine and biology. Circ Res 2016;118:95-107.

24. Regmi S, Pathak S, Kim JO, Yong CS, Jeong JH. Mesenchymal stem cell therapy for the treatment of inflammatory diseases: challenges, opportunities, and future perspectives. Eur J Cell Biol 2019;98:151041.

25. Ciccocioppo R, Baumgart DC, Dos Santos CC, Galipeau J, Klersy C, Orlando G. Perspectives of the international society for cell and gene therapy gastrointestinal scientific committee on the intravenous use of mesenchymal stromal cells in inflammatory bowel disease (PeMeGi). Cytotherapy 2019;21:824-39.
26. Pawitan JA, Yang Z, Wu YN, Lee EH. Towards standardized stem cell therapy in type 2 diabetes mellitus: a systematic review. Curr Stem Cell Res Ther 2018;13:476-88.

27. Galipeau J. The mesenchymal stromal cells dilemma-does a negative phase III trial of random donor mesenchymal stromal cells in steroid-resistant graft-versus-host disease represent a death knell or a bump in the road? Cytotherapy 2013;15:2-8.

28. Srinivasan RC, Kannisto K, Strom SC, Gramignoli R. Evaluation of different routes of administration and biodistribution of human amnion epithelial cells in mice. Cytotherapy 2019;21:113-24

29. Kabat M, Bobkov I, Kumar S, Grumet $M$. Trends in mesenchymal stem cell clinical trials 2004-2018: is efficacy optimal in a narrow dose range? Stem Cells Transl Med 2020;9:17-27

30. Tian S, Hu W, Niu L, Liu H, Xu H, Xiao SY. Pulmonary pathology of early-phase 2019 novel coronavirus (COVID-19) pneumonia in two patients with lung cancer. J Thorac Oncol 2020;15:700-4.

31. Mattar P, Bieback K. Comparing the immunomodulatory properties of bone marrow, adipose tissue, and birthassociated tissue mesenchymal stromal cells. Front Immunol 2015;6:560.

32. WHO. International clinical trials registry platform (ICTRP). Available from: https://www.who.int/ictrp/en/ [Last accessed on 26 Mar 2020]

33. Leng Z, Zhu R, Hou W, Feng Y, Yang Y, Han Q, et al. Transplantation of ACE2-mesenchymal stem cells improves the outcome of patients with COVID-19 pneumonia. Aging Dis 2020;11:216-28.

34. Guan WJ, Ni ZY, Hu Y, Liang WH, Ou CQ, He JX, et al. Clinical characteristics of coronavirus disease 2019 in China. N Engl J Med 2020;382:1708-20.

35. Xie J, Tong Z, Guan X, Du B, Qiu H. Clinical characteristics of patients who died of coronavirus disease 2019 in China. JAMA Netw Open 2020;3:e205619.

36. Jia HP, Look DC, Shi L, Hickey M, Pewe L, Netland J, et al. ACE2 receptor expression and severe acute respiratory syndrome coronavirus infection depend on the differentiation of human airway epithelia. J Virol 2005;79:14614-21.

37. Zhao RC. Stem cell-based therapy for coronavirus disease in 2019. Stem Cells Dev 2020;29:679-81.

38. Liang $\mathrm{B}$, Chen J, Li T, Wu H, Yang W, Li Y, et al. Clinical remission of a critically ill COVID-19 patient treated by human umbilical cord mesenchymal stem cells. Chinaxiv: 202002:0084v1. Available from: http://www.chinaxiv.org/ abs/202002.00084. [Last accessed on 05 May 2020]

39. Terry M. Mesoblast's stem cell therapy shows $83 \%$ survival in ventilator-dependent covid-19 patients. Biospace; 2020 Available from: https://www.biospace.com/article/mesoblastltd-s-stem-cell-therapy-shows-83-percent-survival-in-covid19-patients/ [Last accessed on 27 Apr 2020]

40. Chang D, Mo G, Yuan X, Tao Y, Peng X, Wang FS, et al. Time kinetics of viral clearance and resolution of symptoms in novel coronavirus infection. Am J Respir Crit Care Med 2020;201:1150-2. 